\title{
Clinical utility of adjunctive retigabine in partial onset seizures in adults
}

This article was published in the following Dove Press journal:

Therapeutics and Clinical Risk Management

19 January 2012

Number of times this article has been viewed

\author{
Konrad Rejdak' \\ Jarogniew J Luszczki ${ }^{2,3}$ \\ Barbara Błaszczyk ${ }^{4}$ \\ Roman Chwedorowicz ${ }^{5}$ \\ Stanislaw J Czuczwar ${ }^{2,5}$ \\ 'Department of Neurology, \\ Medical University of Lublin, Lublin, \\ ${ }^{2}$ Department of Pathophysiology, \\ Medical University of Lublin, \\ Lublin, ${ }^{3}$ Isobolography Analysis \\ Laboratory, Institute of Agricultural \\ Medicine, Lublin, ${ }^{4}$ Faculty of Health \\ Sciences, High School of Economics \\ and Law, Kielce, ${ }^{5}$ Department \\ of Physiopathology, Institute of \\ Agricultural Medicine, Lublin, Poland
}

Correspondence: Stanislaw J Czuczwar Department of Pathophysiology, Medical University, Jaczewskiego 8 ,

20-090 Lublin, Poland

Tel +48817187365

Fax +48817187364

Email czuczwarsj@yahoo.com

\begin{abstract}
In $\sim 30 \%$ of epileptic patients, full seizure control is not possible, which is why the search for novel antiepileptic drugs continues. Retigabine exhibits a mechanism of action that is not shared by the available antiepileptic drugs. This antiepileptic enhances potassium currents via Kv7.2-7.3 channels, which very likely results from destabilization of a closed conformation or stabilization of the open conformation of the channels. Generally, the pharmacokinetics of retigabine are linear and the drug undergoes glucuronidation and acetylation. Results from clinical trials indicate that, in the form of an add-on therapy, retigabine proves an effective drug in refractory epileptic patients. The major adverse effects of the add-on treatment are dizziness, somnolence, and fatigue. This epileptic drug is also considered for other conditions - neuropathic pain, affective disorders, stroke, or even Alzheimer's disease.
\end{abstract}

Keywords: antiepileptic drugs, epilepsy, seizure control

\section{Introduction}

Experimental data indicate that epileptic seizures may be associated with an imbalance between inhibitory (represented mainly by the $\gamma$-amino butyric acid [GABA]-ergic system) and excitatory neurotransmission, mediated in general by glutamate in the central nervous system (CNS). ${ }^{1}$ The only exception appears to be absence seizures, probably resulting from an excess of GABA-ergic inhibition, causing $3 \mathrm{~Hz}$ oscillations in the thalamus. ${ }^{1}$ Still, the majority of epileptic seizures depend upon a reduced inhibition and excessive stimulation, and the existing antiepileptic drugs, including both classical and newer ones, through the targeting of the inhibitory or excitatory events restore the proper balance. Some of the drugs enhance GABA-mediated inhibition via a direct or indirect influence on GABA ${ }_{A}$ receptors. Direct GABA enhancers, modulating diverse binding sites on the $\mathrm{GABA}_{\mathrm{A}}$ receptor complex, are benzodiazepines (diazepam, clonazepam), felbamate, phenobarbital, topiramate, and stiripentol. ${ }^{1-3}$ Other antiepileptics reduce the synaptic GABA uptake (tiagabine) or increase the synaptic GABA concentration through the inhibition of its catabolism (valproate or vigabatrin). ${ }^{1,2}$ Also, antiepileptic drugs may reduce glutamate-mediated excitation via a direct blockade of ionotropic glutamate receptors. For instance, phenobarbital or topiramate are $\alpha$-amino-3-hydroxy-5-methyl-4-isoxazolepropionic acid (AMPA) receptor blockers, ${ }^{2}$ and recently, such an activity was ascribed to lamotrigine. ${ }^{4}$ On the other hand, felbamate has been documented to effectively block N-methyl-Daspartate (NMDA) receptors through its potent affinity to the NR2B subunit. ${ }^{5}$ Certainly, some antiepileptic drugs can sufficiently reduce glutamate excitation indirectly. 
For example, carbamazepine, lamotrigine, oxcarbazepine, and topiramate in the range of concentration of $150-1500 \mu \mathrm{M}$ progressively inhibit veratridine-induced glutamate release from the hippocampal nerve endings,${ }^{6}$ whilst carbamazepine, oxcarbazepine, and phenytoin $(500-1500 \mu \mathrm{M})$ have been found effective against high potassium-induced glutamate release in the same experimental model. ${ }^{7}$ Felbamate has been documented to inhibit glutamate release in the rat entorhinal cortex, an effect very likely dependent on the blockade of presynaptic NMDA receptors. ${ }^{8}$ Many antiepileptic drugs control seizure activity through their blockade of voltage-operated sodium or calcium channels. Carbamazepine, lamotrigine, oxcarbazepine, phenytoin, topiramate, and valproate are effective sodium channel blockers. ${ }^{9}$ Ethosuximide and valproate reduce calcium currents via T-type channels, which is probably responsible for their anti-absence activity. ${ }^{2}$ L-type calcium channels are blocked by carbamazepine and topiramate; N-type channels, by levetiracetam; N- and P/Q-type, by gabapentin and pregabalin; N-, P-, and T-type channels, by zonisamide; and N-, P/Q-, R-, and T-channels, by lamotrigine. ${ }^{9}$

Epilepsy as a serious neurologic disorder affects circa 50 million people worldwide, which amounts to about $1 \%$ of the population. ${ }^{1,10}$ Seizures, whose frequency differs considerably between patients, distinctly deteriorate quality of life. ${ }^{11}$ Although antiepileptic drugs remain the main therapeutic option for the management of epilepsy, ${ }^{11}$ there are around $25 \%-30 \%$ of cases that do not fully respond to pharmacotherapy. ${ }^{1}$ From what was stated above, it is evident that both classical (carbamazepine, ethosuximide, phenytoin, phenobarbital, valproate) and newer (gabapentin, lamotrigine, oxcarbazepine, tiagabine, topiramate, or vigabatrin) antiepileptic drugs share similar mechanisms of action, affecting in comparable ways inhibitory and excitatory neurotransmissions or voltage-dependent ion channels. ${ }^{1,2}$ The main advantage of newer antiepileptics is that they exert milder adverse effects, their protective potential being of the same potency as that of classical antiepileptic drugs. ${ }^{1,2,12}$ The mechanism of action of only one newer antiepileptic drug, levetiracetam, is somewhat different from the battery of mechanisms listed above. Levetiracetam binds to the synaptic vesicle protein SV2A, which results in the modulation of neurotransmitter release. ${ }^{13}$

A question arises whether antiepileptic drugs may take advantage of alternative mechanisms which can provide effective anticonvulsant activity along with the beneficial adverse profile. Retigabine (known as ezogabine in the United States), an antiepileptic drug sharing a completely different mechanism of action, is a good example of the search for completely novel antiepileptic drugs.

\section{Structure and metabolites of retigabine}

Chemically, retigabine is an $\mathrm{N}$-(2-amino-4-(4-fluorobenzylamino)phenyl carbamic acid ethyl ester. The drug is subject to glucuronidation in humans and dogs, with the formation of two N-glucuronides: the N2- and the N4-glucuronide. The former metabolite prevails. ${ }^{14,15}$

\section{Pharmacodynamics}

Retigabine, apart from its completely novel mechanism of action involving an enhancement of potassium currents, is also a GABA enhancer. Specifically, the drug has been proved to potentiate GABA-produced chloride currents in rat cortical neurons, and this very effect was evident for a relatively low concentration of retigabine, which amounted to $10 \mu \mathrm{mol} .{ }^{16}$ However, the involvement of benzodiazepine receptors in this effect is unlikely, because flumazenil did not block this particular action of retigabine. ${ }^{16}$ Nevertheless, both retigabine and GABA enhance their binding to the $\mathrm{GABA}_{\mathrm{A}}$ receptor complex and are capable of displacing a $\mathrm{GABA}_{\mathrm{A}}$ receptor tracer ligand, ${ }^{17}$ which may suggest retigabine interaction with the $\mathrm{GABA}_{\mathrm{A}}$ receptor at a place different from the benzodiazepine receptor. Apart from the receptor interactions, the synthesis of GABA has been elevated by retigabine in rat hippocampal slices. ${ }^{18}$

As already mentioned above, retigabine is a modulator of potassium currents. Kv7 potassium channel (formerly known as KCNQ channel) is composed of five subunits, and apart from the Kv7.1, the remaining subunits (Kv7.2-7.5) are present in the nervous system. ${ }^{19}$ These four subunits conduct the low-threshold voltage-gated potassium current and form the "M-channel." In most neurons, the M-channel is mainly composed of Kv7.2-7.3 subunits. ${ }^{19}$ Retigabine has been found as an effective potassium channel opener. The specificity of this effect is of great magnitude as this antiepileptic drug is still effective in this regard in as low concentration as $0.1 \mu \mathrm{mol} .^{20}$ The opening of the potassium channels by retigabine and the subsequent hyperpolarization in rat hippocampal-entorhinal slices is very likely to result from this specific effect. ${ }^{21}$ Further studies on the retigabine $(0.1-10.0 \mu \mathrm{mol})$-induced neuronal outward current have revealed that this drug considerably potentiates Kv7.2-7.3 currents, and this particular action is probably related to destabilization of a closed conformation or stabilization of the open conformation of the Kv7.2-7.3 channels. ${ }^{22}$ The Kv7.2-7.3 channel blocker, linopridine 
(at $10 \mu \mathrm{mol}$ ) inhibits retigabine-induced outward potassium channels. $^{22}$

The retigabine's mechanism of action and that of some reference antiepileptic drugs is displayed in Table 1.

\section{Pharmacokinetics and metabolism}

In contrast to the majority of classical and some newer antiepileptic drugs, retigabine does not undergo any hepatic metabolism via cytochrome P-450 enzymes. ${ }^{23}$ Primarily, the drug is subject to glucuronidation to form N-glucuronide metabolites or to acetylation, which results in its conversion to mono-acetylated metabolite - AWD21-360. 23,24 Human or dog metabolism of retigabine is mainly dependent on glucuronidation; whilst in rats, there are a couple of different metabolic pathways forming multiple metabolites of this antiepileptic drug. ${ }^{24}$ In humans and dogs, there is a constant ratio between unmetabolized retigabine and its N-glucuronide. ${ }^{14}$ The constant ratio may be indicative of a coupling between concentrations of retigabine and its metabolite through enterohepatic circulation and reactions of glucuronidation/deglucuronidation. ${ }^{14}$ In healthy volunteers on an oral daily dose of $600 \mathrm{mg}$ of retigabine, evaluation of samples of plasma and urine have provided evidence on the existence of two metabolic pathways - glucuronidation and acetylation. $^{23}$

Within the dose range of the first dose (100-350 mg and then twice daily for a fortnight), retigabine's pharmacokinetics were linear and dose-dependent when evaluated in healthy white and black volunteers. ${ }^{25}$ After a single dose of $200 \mathrm{mg}$, a rapid absorption was noted, the mean maximum plasma concentration reaching $819 \mathrm{ng} / \mathrm{mL}$ within the mean time of 1.6 hours. In white volunteers, the mean apparent terminal half-life was 8 hours with the accompanying apparent clearance of $0.70 \mathrm{~L} \times \mathrm{h}^{-1} \times \mathrm{kg}^{-1}$; whilst in the black volunteers, the respective parameters were $25 \%$ and $30 \%$ lower. $^{25}$

Similar results have been documented by Hermann et al, ${ }^{15}$ who after a single dose of the antiepileptic in young men aged 18-40 years, estimated the mean terminal half-life of 8.5 hours with the apparent clearance of $0.67 \mathrm{~L} \times \mathrm{h}^{-1} \times \mathrm{kg}^{-1}$. However, the mean maximum concentration was considerably lower (420 ng/mL), and the time to reach it was somewhat longer ( 2 hours). ${ }^{15}$

There are also data available on the effects of some other antiepileptic drugs on the pharmacokinetic parameters of retigabine in healthy volunteers. As regards to phenobarbital, this antiepileptic did not modify pharmacokinetics of retigabine, indicating that phenobarbital is likely to possess no influence on the retigabine's metabolism. ${ }^{26}$ When combined with lamotrigine in healthy subjects, the retigabine's clearance was reduced by $13 \%$, and its mean half-life as well as area under the plasma concentration-time curve were increased by $7.5 \%$ and $15 \%$, respectively. ${ }^{27}$ These authors present the view, that a competition between both drugs for renal excretion, but not for glucuronidation, might explain this interaction. ${ }^{27}$ They have also examined an impact of retigabine on the pharmacokinetics of lamotrigine, proving that lamotrigine's metabolism is enhanced to a moderate degree - its apparent clearance being increased by $22 \%$, and its mean half-life along with the area under the plasma concentration-time curve reduced by $15 \%$ and $18 \%$, respectively. The authors of that study ${ }^{27}$ are of the opinion that this interaction is not likely to result from the induction by retigabine of metabolizing enzymes because this antiepileptic was without any significant influence upon the pharmacokinetics of carbamazepine, phenobarbital, phenytoin, topiramate, and valproate in epileptic patients. ${ }^{26,28}$

Table I Mechanisms of action of RTG compared with those of other AEDs: VPA, LTG, TPM, OXC, CBZ, TGB, VGB, and GBP

\begin{tabular}{llllll}
\hline AEDs & $\begin{array}{l}\text { Enhancement of GABA- } \\
\text { mediated inhibition }\end{array}$ & $\begin{array}{l}\text { Inhibition of } \\
\text { glutamate excitation }\end{array}$ & $\begin{array}{l}\text { Blockade of } \\
\text { calcium channels }\end{array}$ & $\begin{array}{l}\text { Blockade of } \\
\text { sodium channels }\end{array}$ & $\begin{array}{l}\text { Enhancement of } \\
\text { potassium currents }\end{array}$ \\
\hline RTG & + & $\mathrm{NE}$ & $\mathrm{NE}$ & $\mathrm{NE}$ & + \\
$\mathrm{VPA}$ & $+/-$ & + & $+(\mathrm{T}$-type $)$ & $+/-$ & $\mathrm{NE}$ \\
$\mathrm{LTG}$ & $\mathrm{NE}$ & + & $+(\mathrm{N}, \mathrm{P} / \mathrm{Q}, \mathrm{R}, \mathrm{T})$ & + & $\mathrm{NE}$ \\
$\mathrm{TPM}$ & + & + & $+(\mathrm{L})$ & + & $\mathrm{NE}$ \\
$\mathrm{OXC}$ & $\mathrm{NE}$ & $\mathrm{NE}$ & $+(\mathrm{N}, \mathrm{P})$ & + & $\mathrm{NE}$ \\
$\mathrm{CBZ}$ & $\mathrm{NE}$ & $\mathrm{NE}$ & $+(\mathrm{L})$ & + & $\mathrm{NE}$ \\
TGB & + & $\mathrm{NE}$ & $\mathrm{NE}$ & $\mathrm{NE}$ \\
VGB & + & $\mathrm{NE}$ & $\mathrm{NE}$ & $\mathrm{NE}$ & $\mathrm{NE}$ \\
$\mathrm{GBP}$ & + & $\mathrm{NE}$ & $+(\mathrm{N}, \mathrm{P} / \mathrm{Q})$ & $\mathrm{NE}$ & $\mathrm{NE}$ \\
\hline
\end{tabular}

Notes: +, well documented mechanism of action; NE, not effective at therapeutic AED concentrations; +/-, controversial results. Data are from Czuczwar and Patsalos,' Czapinski et al, ${ }^{2}$ Sitges et al, ${ }^{6}$ Sitges et al, ${ }^{7}$ and Perucca. ${ }^{9}$

Abbreviations: AED, antiepileptic drug; CBZ, carbamazepine; GABA, $\gamma$-amino butyric acid; GBP, gabapentin; LTG, lamotrigine; OXC, oxcarbazepine; RTG, retigabine; TGB, tiagabine; TPM, topiramate; VGB, vigabatrin; VPA, valproate. 


\section{Activity and toxicity in experimental models of epilepsy}

Retigabine is effective in a variety of experimental models of epileptic seizures - the drug inhibits maximal electroshock-, pentylenetetrazol-, N-methyl-D-aspartate-, kainate-, picrotoxin-, and sound-induced seizure activity in rodents. ${ }^{13}$ Also, in doses producing no or mild adverse effects, retigabine is effective in elevating the after-discharge threshold and reducing the after-discharge duration in fully hippocampal-kindled rats. ${ }^{29}$ Remarkably, retigabine in three age groups of young rats (P14, P21, and P35) was capable of inhibiting the evolution of kindling to the maximum stage, and in one group (P14), it distinctly delayed the acquisition of focal convulsions. These data may lead to a conclusion that apart from the apparent anticonvulsant activity, retigabine possesses an antiepileptogenic potential as well. ${ }^{29}$ It is remarkable that the developmental profile of another potent antiepileptic drug, topiramate, was quite distinct in that this drug, in contrast to retigabine, was least effective in P14 rats. ${ }^{30}$ Nevertheless, retigabine was much weaker as an anticonvulsant in mutant Sz1 mice that were deprived of most of the C-terminus in their Kv7.2 channels, whilst its potent anticonvulsant activity against partial psychomotor seizures was not affected in the littermate control. ${ }^{31}$

Retigabine does not exert any harmful activity upon reproductive functions in rats, and no teratogenic potential of this antiepileptic has been found in rats or rabbits. ${ }^{32}$ Perinatal or postnatal treatment with retigabine is not associated with any developmental toxicity, the only exception being the animals injected with the highest dose of this antiepileptic drug, whose growth is significantly reduced. ${ }^{32}$

Acute toxicity evaluations have revealed that in different animal species, retigabine induces a number of toxic effects, mainly derived from the CNS - hypo- or hyperkinesia, uncoordinated movements, tremor, stilted gait, and convulsions. However, electroencephalographic parameters were not affected by retigabine in isolated guinea-pig heart or in vivo in dogs (orally up to $38 \mathrm{mg} / \mathrm{kg}$ for a week). ${ }^{32}$

\section{Interactions of retigabine with classical and newer antiepileptic drugs in mice}

Combinations of retigabine with classical or newer antiepileptic drugs have been evaluated experimentally with the use of two methods. One method assumed the combined treatment of retigabine at subprotective doses with active doses of other antiepileptics. Based on this experimental approach, De Sarro et $\mathrm{al}^{33}$ have found that retigabine at $0.5 \mathrm{mg} / \mathrm{kg}$ potentiated the anticonvulsant activity of carbamazepine, diazepam, felbamate, lamotrigine, phenytoin, phenobarbital, and valproate against soundinduced convulsions in DBA/2 mice. The most distinct reductions in the respective $\mathrm{ED}_{50}$ values were observed for diazepam, phenobarbital, phenytoin, and valproate. The protective indices for the combined treatments were better than that for retigabine alone. The observed interactions may be interpreted in terms of pharmacodynamic mechanisms, because in no case did retigabine change the total or free plasma concentrations of the studied antiepileptic drugs. ${ }^{33}$

With a method of isobolographic analysis, one can accurately evaluate the final effects of a drug combination as synergistic, additive, or antagonistic. ${ }^{34}$ In the test of maximal electroshock in mice, the dose-effect curves for retigabine and valproate were parallel, so it was possible to assess their interaction in fixed-dose ratios other than just 1:1. It is noteworthy that in three dose ratios of 1:3,1:1, and 3:1, the combination of retigabine + valproate proved synergistic against maximal electroshock in mice. However, the dose effects curves for retigabine and carbamazepine or lamotrigine were not parallel, and consequently, only one fixed-dose ratio of 1:1 of these drugs could be evaluated. In both cases (retigabine + carbamazepine or retigabine + lamotrigine) additivity was noted against maximal electroshock-induced convulsions in mice. Neurotoxic evaluation has indicated that no evaluated combination was associated with disturbed motor coordination, long-term memory, or muscular strength. Determinations of the concentrations of all drugs in a given combined treatment have revealed that only in the fixed dose ratio of 3:1 (retigabine:valproate) combination, the free plasma and total brain levels of valproate were elevated. ${ }^{34}$

\section{Clinical efficacy, safety, and tolerability}

Initial clinical evidence indicated that retigabine both as mono- or polytherapy in 15 healthy volunteers was in principle well tolerated. Headache was most frequently reported, and there were no laboratory test or ECG disturbances. The drug had to be withdrawn in one epileptic patient due to severe abdominal pain. ${ }^{26}$

Retigabine was subsequently studied as an add-on drug in patients with partial onset seizures within a Phase II multicenter, randomized, placebo-controlled clinical trial, being titrated to daily doses of 600,900 , and $1200 \mathrm{mg}$ over a period of 2-6 weeks. ${ }^{35}$ The respective responder rates for these doses were $23 \%, 32 \%$, and $33 \%$ versus $16 \%$ for placebo, 
which reached the level of significance except for the dose of $600 \mathrm{mg}$. The most frequently reported adverse effects were somnolence, dizziness, confusion, speech disorder, vertigo, tremor, amnesia, abnormal thinking, abnormal gait, paresthesia, and diplopia. ${ }^{35}$

Finally, the drug was tested in two Phase III multicenter, randomized, double-blind studies in which retigabine was added to 1-3 antiepileptic drugs, ${ }^{32}$ and the results of these trials led to formal registration of the drug by the European Medicines Agency and the Food and Drug Administration. The first study, sponsored by Valeant ${ }^{36}$ and registered as RESTORE 1 assumed titration of this antiepileptic to $1200 \mathrm{mg}$. There were two periods of observation: an 8-week, prospective baseline phase and an 18-week double-blind treatment period (with 6-week initial dose titration phase). Two primary endpoints were considered: percentage change in 28-day total partial seizure frequency between baseline and double-blind period, and responder rate, defined as $50 \%$ reduction in 28-day total partial seizure frequency between baseline and maintenance phase. A total of 306 patients were randomized, and 305 of those were used in the intention-to-treat analysis. The retigabine treatment group had $44.3 \%$ reduction in monthly seizure frequency compared with $17.5 \%$ in the placebo group $(P=0.001)$. Responder rate was $44.4 \%$ in the treated group, while $17.8 \%$ in the placebo group $(P=0.001)$. During the maintenance phase, $5 \%$ of patients in the treated group were seizure-free compared with $1 \%$ in the placebo group, but the difference did not reach statistical significance. However, the percentage of seizure-free days in the treated group was significantly greater than in the placebo group. The proportion of patients discontinuing due to treatment-emergent adverse events (TEAEs) was 26.8\% (retigabine) versus $8.6 \%$ (placebo). Dizziness, somnolence, fatigue, confusion, dysarthria, urinary tract infection, ataxia, and blurred vision were the most common TEAEs reported by more patients treated with retigabine than placebo. ${ }^{36}$ The second study, known as RESTORE 2, was also sponsored by Valeant. ${ }^{37}$ The study was designed with four phases: a prospective 8-week baseline, 4-week titration up to $600 \mathrm{mg}$ /day or $900 \mathrm{mg}$ /day, 12-week maintenance, and a 4-week transition phase if patients elected to participate in the open-label extension phase. A total of 539 patients were randomized, and 538 patients were included in the intention-to-treat analysis. The median percentage reduction was greater for both the $600 \mathrm{mg} /$ day $(27.9 \%, P=0.007)$ and $900 \mathrm{mg} /$ day $(39.9 \%$, $P=0.001)$ treatment groups compared with placebo (15.9\%). Responder rate defined as $50 \%$ reduction in seizure frequency was significantly higher in both the $600 \mathrm{mg} /$ day $(38.6 \%)$ and the $900 \mathrm{mg} /$ day (47.0\%) group than in placebo-treated patients $(18.9 \%, P=0.001)$. Treatment discontinuations due to adverse events (AEs) were more likely with retigabine than with placebo (placebo, 8\%; $600 \mathrm{mg}, 17 \%$; $900 \mathrm{mg}, 26 \%$ ). The most commonly reported $(>10 \%)$ AEs in the placebo, retigabine $600 \mathrm{mg} /$ day and $900 \mathrm{mg} /$ day groups were dose dependent and included dizziness $(7 \%, 17 \%, 26 \%$, respectively), somnolence $(10 \%, 14 \%, 26 \%)$, headache $(15 \%, 11 \%$, $17 \%)$, and fatigue $(3 \%, 15 \%, 17 \%) .{ }^{37}$

Except CNS-related effects, there is another issue which deserves special attention. There was some experimental evidence that retigabine had adverse effects on bladder function in a rat model. Investigators from RESTORE 1 and 2 studies performed detailed evaluation of all possible adverse reactions from urinary tract in retigabine-treated patients. In RESTORE 2, three patients on retigabine reported chromaturia, and three patients complained of adverse events of the urinary tract (one nephritis and two urinary retention). The RESTORE 1 study revealed that 15 of the retigabine-treated patients had increased post-void residual volumes compared with six of the placebo-treated patients. Among other AEs reported were urinary tract infection, urinary hesitation, dysuria, and chromaturia. In general, the safety profile in both studies was good and no serious adverse effects were reported.

RESTORE 1 and 2 were actually randomized controlled short-term studies, and there are no results available as yet on long-term efficacy and safety of retigabine in epileptic patients.

Looking to the future, there are several clinical issues to be studied with regard to retigabine treatment in epilepsy patients. It would be very important to assess the clinical spectrum for different seizure types, especially absence, tonic-clonic, as well as myoclonic generalized seizures both in pediatric or adult populations, especially when used in newly diagnosed epilepsy. In addition, studies on the efficacy of retigabine in pediatric patients with partial-onset seizures or Lennox-Gastaut syndrome have been planned. ${ }^{32}$ There is experimental evidence that retigabine has broad anticonvulsant activity when used in various models of generalized seizures. ${ }^{38}$ Similarly, the efficacy and safety of the drug should be studied in special populations like elderly patients, women in child-bearing age, and patients with intellectual disability. Particular attention should be put on co-morbidities including diseases of the urinary tract, having in mind the known effects of the drug on urinary retention. Above aspects will definitely be taken up in future post-marketing studies to provide more data on possible applications of the drug in wide clinical practice. 


\section{Nonepilepsy potential of retigabine}

Antiepileptic drugs have been shown effective in conditions other than epilepsy, and their clinical use in neuropathic pain, migraine, affective disorders, spasticity, or restless legs syndrome has been approved.$^{39}$ There are experimental data indicating that retigabine inhibits neuropathic pain in models of chronic constriction injury and spared nerve or in the formalin test. ${ }^{40,41}$ The drug is also likely to exert some antimanic activity as it distinctly counteracts enhanced locomotor activity by amphetamine + chlordiazepoxide in rats. ${ }^{42}$ Retigabine has also been proved to attenuate the psychostimulatory effects of cocaine, methylphenidate, or phencyclidine and thus may be considered as an anti-addictive drug. ${ }^{43}$ Other basic studies have provided evidence that retigabine actually exerts anxiolytic and antidystonic effects. ${ }^{44,45}$ Some case reports and even a clinical trial indicate that retigabine may delay the progression of Alzheimer's disease. ${ }^{46,47}$ Possible nonepilepsy uses of retigabine are listed and compared with those of other antiepileptic drugs in Table 2.

\section{Final considerations}

Although many newer antiepileptic drugs have been available in the last two decades, the percentage of drug-resistant patients has not significantly improved. ${ }^{1,2,12}$ One possible reason for this apparent failure may be that newer antiepileptic drugs are usually added to the existing antiepileptic treatment in drugresistant patients. Thus, such a therapeutic approach is independent of the existing treatment, and the antiepileptic drugs are combined randomly. Considering experimental data on the combined treatment, it is evident that the final outcome of a drug interaction may be synergy, additivity, or antagonism. ${ }^{48}$ It would be thus reasonable to consider drug combinations exerting anticonvulsant synergy from both experimental ${ }^{48}$ and clinical points of view. ${ }^{49}$ In this context, best therapeutic results with retigabine as an add-on drug, would be expected in its combination with valproate, which is purely synergistic. ${ }^{34}$
Combinations of carbamazepine + retigabine or lamotrigine + retigabine might be less clinically effective. ${ }^{34}$

The adverse profile of retigabine is in fact the result of its interactions with the existing antiepileptic treatment. So far, there are no data available on the tolerability of retigabine applied in the form of monotherapy.

Some reports indicate that retigabine may exert neuroprotective effects in some brain areas (eg, pyriform cortex) in vivo after kainate-induced status epilepticus in rats. ${ }^{50}$ Also, there are data on its neuroprotective action in vitro. ${ }^{51}$ However, the significance of these findings in terms of epileptogenesis may be unclear since there is no distinct link between these two events. ${ }^{50}$

The research on positive potassium channel modulators is growing very fast. There is currently a compound available, which contrary to retigabine, may activate the mutated Kv7.2 channel. This finding can actually broaden the practical utility of potassium channel activators. ${ }^{52}$

To date, there are several reviews devoted to retigabine (the last four being published in 2011). ${ }^{53-61}$ Whilst dealing with generally similar points (pharmacokinetics and pharmacodynamics of retigabine along with its clinical efficacy and adverse effects), this review is also focused on the effectiveness of retigabine in combinations with other antiepileptic drugs as well on its nonepilepsy potential, which is also mentioned by Weisenberg and Wong. ${ }^{59}$

\section{Conclusion}

Retigabine is the first antiepileptic drug able to enhance neuronal potassium currents, and this effect is blocked by the Kv7.2-7.3 channel blocker linopridine. ${ }^{22}$ This antiepileptic has shown a good experimental profile in interactions with valproate (anticonvulsant synergy) or carbamazepine and lamotrigine (anticonvulsant additivity). ${ }^{34}$

Clinically, in patients with refractory epilepsy, retigabine in the form of an add-on therapy, led to considerable improvement, reflected by a significant reduction in seizure

Table 2 Nonepilepsy uses of RTG and other AEDs: CBZ, GBP, LTG, OXC, and TPM

\begin{tabular}{|c|c|c|c|c|c|}
\hline \multirow[t]{2}{*}{ AEDs* } & \multicolumn{5}{|c|}{ Nonepilepsy indications } \\
\hline & $\begin{array}{l}\text { Neuropathic } \\
\text { pain }\end{array}$ & $\begin{array}{l}\text { Bipolar } \\
\text { disorder }\end{array}$ & Dystonia & $\begin{array}{l}\text { Cocaine } \\
\text { addiction }\end{array}$ & $\begin{array}{l}\text { Alzheimer's } \\
\text { disease }\end{array}$ \\
\hline RTG & $t^{a}$ & $t^{\mathrm{a}}$ & $t^{\mathrm{a}}$ & $t^{a}$ & $t^{\mathrm{a}, \mathrm{b}}$ \\
\hline CBZ & $+/-$ & + & $+^{c}$ & $+/-$ & + \\
\hline GBP & + & $+/-$ & $+/-$ & $+/-$ & $+^{d}$ \\
\hline LTG & + & + & $--^{\mathrm{a}}$ & $+/-$ & $+^{\mathrm{d}}$ \\
\hline OXC & + & $+/-$ & + & + & - \\
\hline TPM & $+/-$ & $+/-$ & + & $+/-$ & + \\
\hline
\end{tabular}

Notes: +, drug effective; +/-, controversial data; -, drug ineffective; aexperimental data; 'initial clinical data; 'dystonia as a result of drug toxicity; dimited number of patients. *All data are from references, ${ }^{39,62-79}$ except for RTG, which are from references. ${ }^{40-43,45-47}$

Abbreviations: AED, antiepileptic drug; CBZ, carbamazepine; GBP, gabapentin; LTG, lamotrigine; OXC, oxcarbazepine; RTG, retigabine; TPM, topiramate. 
frequency with an accompanying good tolerability profile. ${ }^{32,35}$ There are also data available showing that the clinical use of retigabine may be considered also for nonepilepsy indications (eg, neuropathic pain, mania, possibly bipolar disorder, stroke, and Alzheimer's disease). ${ }^{40-42,46,47}$

\section{Disclosure}

K Rejdak and SJ Czuczwar have lectured for GlaxoSmith Kline. SJ Czuczwar and JJ Luszczki published a paper $^{34}$ with JZ Wu, as a co-author, from Valeant Pharmaceuticals International. Other authors report no conflicts of interests in this work.

\section{References}

1. Czuczwar SJ, Patsalos PN. The new generation of GABA enhancers. Potential in the treatment of epilepsy. CNS Drugs. 2001;15(5):339-350.

2. Czapinski P, Blaszczyk B, Czuczwar SJ. Mechanism of action of antiepileptic drugs. Curr Top Med Chem. 2005;5(1):3-14.

3. Czuczwar SJ, Trojnar MK, Gergont A, Kroczka S, Kaciński M. Stiripentol - characteristic of a new antiepileptic drug. Expert Opin Drug Discov. 2008;5(2):453-460.

4. Lee CY, Fu WM, Chen CC, Su MJ, Liou HH. Lamotrigine inhibits postsynaptic AMPA receptor and glutamate release in the dentate gyrus. Epilepsia. 2008;49(5):888-897.

5. Harty TP, Rogawski MA. Felbamate block of recombinant N-methylD-aspartate receptors: selectivity for the NR2B subunit. Epilepsy Res. 2000;39(1):47-55.

6. Sitges M, Chiu LM, Guarneros A, Nekrassov V. Effects of carbamazepine, phenytoin, lamotrigine, oxcarbazepine, topiramate and vinpocetine on $\mathrm{Na}^{+}$channel-mediated release of $\left[{ }^{3} \mathrm{H}\right]$ glutamate in hippocampal nerve endings. Neuropharmacology. 2007;52(2):598-605.

7. Sitges M, Guarneros A, Nekrassov V. Effects of carbamazepine, phenytoin, valproic acid, oxcarbazepine, topiramate and vinpocetine on the presynaptic $\mathrm{Ca}^{2+}$ channel-mediated release of $\left[{ }^{3} \mathrm{H}\right]$ glutamate: comparison with the $\mathrm{Na}^{+}$channel-mediated release. Neuropharmacology. 2007;53(7):854-862.

8. Yang J, Wetterstrand C, Jones RS. Felbamate but not phenytoin or gabapentin reduces glutamate release by blocking presynaptic NMDA receptors in the entorhinal cortex. Epilepsy Res. 2007;77(2-3):157-164.

9. Perucca E. An introduction to antiepileptic drugs. Epilepsia. 2005; 46(Suppl 4):31-37.

10. Gilliam FG. Diagnosis and treatment of mood disorders in persons with epilepsy. Curr Opin Neurol. 2005;18(2):129-133.

11. de Boer HM, Mula M, Sander JW. The global burden and stigma of epilepsy. Epilepsy Behav. 2008;12(4):540-546.

12. Sanchez Alvarez JC, Serrano Castro PJ, Serratosa Fernandez JM Clinical implications of mechanisms of resistance to antiepileptic drugs. Neurologist. 2007;13(Suppl 1):S38-S46.

13. Luszczki JJ. Third-generation antiepileptic drugs: mechanisms of action, pharmacokinetics and interactions. Pharmacol Rep. 2009;61(2): 197-216.

14. Hiller A, Nguyen N, Strassburg CP, et al. Retigabine N-glucoronidation and its potential role in enterohepatic circulation. Drug Metab Disp. 1999;27(5):605-612.

15. Hermann R, Ferron GM, Erb K, et al. Effects of age and sex on the disposition of retigabine. Clin Pharmacol Ther. 2003:73(1):61-70.

16. Rundfeldt $C$, Netzer R. Investigations into the mechanism of action of the new anticonvulsant retigabine. Interaction with GABAergic and glutamatergic neurotransmission and with voltage gated ion channels. Arzneimittelforschung. 2000;50(12):1063-1070.

17. Van Rijn CM, Willems-van Bree E. Synergy between retigabine and GABA in modulating the convulsant site of the $\mathrm{GABA}_{\mathrm{A}}$ receptor complex. Eur J Pharmacol. 2003;464(2-3):95-100.
18. Kapetanovic IM, Yonekawa WD, Kupferberg HJ. The effects of D-23129, a new experimental anticonvulsant drug, on neurotransmitter amino acids in the rat hippocampus in vitro. Epilepsy Res. 1995;22(3):167-173.

19. Brown DA, Passmore GM. Neural KCNQ (Kv7) channels. $B r J$ Pharmacol. 2009;156(8):1185-1195.

20. Rundfeldt $C$. The new anticonvulsant retigabine (D-23129) acts as an opener of $\mathrm{K}^{+}$channels in neuronal cells. Eur J Pharmacol. 1997; 336(2-3):243-249.

21. Hetka R, Rundfeldt C, Heinemann U, Schmitz D. Retigabine strongly reduces repetitive firing in rat entorhinal cortex. Eur J Pharmacol. 1999;386(2-3):165-171.

22. Wickenden AD, Yu W, Zou A, Jegla T, Wagoner PK. Retigabine, a novel anti-convulsant, enhances activation of KCNQ2/Q3 potassium channels. Mol Pharmacol. 2000;58(3):591-600.

23. Hempel R, Schupke H, McNeilly PJ, et al. Metabolism of retigabine (D-23129), a novel anticonvulsant. Drug Metab Dispos. 1999;27(5): 613-622.

24. McNeilly PJ, Torchin CD, Anderson LW, Kapetanovic IM, Kupferberg HJ, Strong JM. In vitro glucuronidation of D-23129, a new anticonvulsant, by human liver microsomes and liver slices. Xenobiotica. 1997;27(5):431-441.

25. Ferron GM, Paul J, Fruncillo R, et al. Multiple dose, linear, doseproportional pharmacokinetics of retigabine in healthy volunteers. J Clin Pharmacol. 2002;42(2):175-182.

26. Ferron GM, Patat A, Parks V, Rolan P, Troy SM. Lack of pharmacokinetic interaction between retigabine and phenobarbitone at steady-state in healthy subjects. Br J Clin Pharmacol. 2003;56(1):39-45.

27. Hermann R, Knebel NG, Niebch G, Richards L, Borlak J, Locher M. Pharmacokinetic interaction between retigabine and lamotrigine in healthy subjects. Eur J Clin Pharmacol. 2003;58(12):795-802.

28. Bialer M, Johannessen SI, Kupferberg HJ, Levy RH, Loiseau P, Perucca E. Progress report on new antiepileptic drugs: a summary of Sixth Eilat Conference. Epilepsy Res. 2002;51(1-2):31-71.

29. Mazarati A, Wu J, Shin D, Kwon YS, Sankar R. Antiepileptogenic and antiictogenic effects of retigabine under conditions of rapid kindling: an ontogenic study. Epilepsia. 2008;49(10):1777-1786.

30. Sankar R, Auvin S, Kwon YS, Pineda E, Shin D, Mazarati A. Evaluation of development-specific targets for antiepileptogenic therapy using rapid kindling. Epilepsia. 2010;51(Suppl 3):39-42.

31. Otto JF, Yang Y, Frankel WM, Wilcox KS, White HS. Mice carrying the szt1 mutation exhibit increased seizure susceptibility and altered sensitivity to compounds acting at the m-channel. Epilepsia. 2004; 45(9):1009-1016.

32. Bialer M, Johannessen SI, Levy RH, Perucca E, Tomson T, White HS. Progress report on new antiepileptic drugs: a summary of the Ninth Eilat Conference (EILAT IX). Epilepsy Res. 2009;83(1):1-43.

33. De Sarro G, Di Paola ED, Conte G, Pasculli MP, De Sarro A. Influence of retigabine on the anticonvulsant activity of some antiepileptic drugs against audiogenic seizures in DBA/2 mice. Naunyn-Schmiedeb Arch Pharmacol. 2001;363(3):330-336.

34. Luszczki JJ, Wu JZ, Raszewski G, Czuczwar SJ. Isobolographic characterization of interactions of retigabine with carbamazepine, lamotrigine and valproate in the mouse maximal electroshock-induced seizure model. Naunyn-Schmiedeb Arch Pharmacol. 2009;379(2):163-179.

35. Porter RJ, Partiot A, Sachdeo R, Nohria V, Alves WM; 205 Study Group. Randomized, multicenter, dose-ranging trial of retigabine for partial-onset seizures. Neurology. 2007;68(15):1197-1204.

36. French JA, Abou-Khalil BW, Leroy RF, et al. Randomized, doubleblind, placebo-controlled trial of ezogabine (retigabine) in partial epilepsy. Neurology. 2011;76(18):1555-1563.

37. Brodie MJ, Lerche H, Gil-Nagel A, et al. Efficacy and safety of adjunctive ezogabine (retigabine) in refractory partial epilepsy. Neurology. 2010;75(20):1817-1824.

38. Rostock A, Tober C, Rundfeldt C, et al. (1996) D-23129: a new anticonvulsant with a broad spectrum activity in animal models of epileptic seizures. Epilepsy Res. 1996;23(3):211-223. 
39. Zaremba P, Białek M, Błaszczyk B, Cioczek P, Czuczwar SJ. Non-epilepsy uses of antiepileptic drugs. Pharmacol Rep. 2006;58(1):1-12.

40. Blackburn-Munro G, Jensen BS. The anticonvulsant retigabine attenuates nociceptive behaviours in rat models of persistent and neuropathic pain. Eur J Pharmacol. 2003;460(2-3):109-116.

41. Munro G, Erichsen HK, Mirza NR. Pharmacological comparison of anticonvulsant drugs in animal models of persistent pain and anxiety. Neuropharmacology. 2007;53(5):609-618.

42. Dencker D, Dias R, Pedersen ML, Husum H. Effect of the new antiepileptic drug retigabine in a rodent model of mania. Epilepsy Behav. 2008;12(1):49-53.

43. Hansen HH, Andreasen JT, Weikop P, Mirza N, Scheel-Krüger J, Mikkelsen JD. The neuronal KCNQ channel opener retigabine inhibits locomotor activity and reduces forebrain excitatory responses to the psychostimulants cocaine, methylphenidate and phencyclidine. Eur $J$ Pharmacol. 2007;570(1-3):77-88.

44. Korsgaard MP, Hartz BP, Brown WD, Ahring PK, Strobaek D, Mirza NR. Anxiolytic effects of Maxipost (BMS-204352) and retigabine via activation of neuronal Kv7 channels. J Pharmacol Exp Ther. 2005; 314(1):282-292.

45. Richter A, Sander SE, Rundfeldt C. Antidystonic effects of Kv7 (KCNQ) channel openers in the dt sz mutant, an animal model of primary paroxysmal dystonia. Br J Pharmacol. 2006;149(6):747-753.

46. Surti TS, Jan LY. A potassium channel, the M-channel, as a therapeutic target. Curr Opin Investig Drugs. 2005;6(7):704-711.

47. Gongadze N, Antelawa N, Kezeli T, Okudjava M, Pachkoria K. The mechanisms of neurodegenerative processes and current pharmacotherapy of Alzheimer's disease. Georgian Med News. 2008;155:44-48.

48. Czuczwar SJ, Kaplanski J, Swiderska-Dziewit G, Gergont A, Kroczka S, Kacinski M. Pharmacodynamic interactions between antiepileptic drugs: preclinical data based on isobolography. Expert Opin Drug Metab Toxicol. 2009;5(2):131-136.

49. Stephen LJ, Brodie MJ. Seizure freedom with more than one antiepileptic drug. Seizure. 2002;11(6):349-351.

50. Ebert U, Brandt C, Löscher W. Delayed sclerosis, neuroprotection, and limbic epileptogenesis after status epilepticus in the rat. Epilepsia. 2002;43(Suppl 5):86-95.

51. Boscia F, Annunziato L, Tagliatella M. Retigabine and flupirtine exert neuroprotective actions in organotypic hippocampal cultures. Neuropharmacology. 2006;51(2):283-294.

52. Gao Z, Zhang T, Wu M, et al. Isoform-specific prolongation of Kv7 (KCNQ) potassium channel opening mediated by new molecular determinants for drug-channel interactions. $J$ Biol Chem. 2010;285(36):28322-28332.

53. Blackburn-Munro G, Dalby-Brown W, Mirza NR, Mikkelsen JD, Blacburn-Munro RE. Retigabine: chemical synthesis to clinical application. CNS Drug Rev. 2005;11(1):1-20.

54. Plosker GL, Scott LJ. Retigabine in partial seizures. CNS Drugs. 2006;20(7):601-608.

55. Porter RJ, Nohria V, Rundfeldt C. Retigabine. Neurotherapeutics. 2007;4(1):149-154.

56. Czuczwar P, Wojtak A, Cioczek-Czuczwar A, Parada-Turska J, Maciejewski R, Czuczwar SJ. Retigabine: the newer potential antiepileptic drug. Pharmacol Rep. 2010;62(2):211-219.

57. Owen RT. Ezogabine: a novel antiepileptic as adjunctive therapy for partial onset seizures. Drugs Today. 2010;46(11):815-822.

58. Faught E. Ezogabine: a new angle on potassium gates. Epilepsy Curr. 2011;11(3):75-78.

Therapeutics and Clinical Risk Management

\section{Publish your work in this journal}

Therapeutics and Clinical Risk Management is an international, peerreviewed journal of clinical therapeutics and risk management, focusing on concise rapid reporting of clinical studies in all therapeutic areas, outcomes, safety, and programs for the effective, safe, and sustained use of medicines. This journal is indexed on PubMed Central, CAS,
59. Weisenberg JL, Wong M. Profile of ezogabine (retigabine) and its potential as an adjunctive treatment for patients with partial-onset seizures. Neuropsychiat Dis Treat. 2011;7:409-414.

60. Stafstrom CE, Grippon S, Kirkpatrick P. Ezogabine (retigabine). Nat Rev Drug Discov. 2011;10(10):729-730.

61. Deeks ED. Retigabine (ezogabine): in partial onset seizures in adults with epilepsy. CNS Drugs. 2011;25(10):887-900.

62. Lima Reisser AA, Silva de Lima M, Soares BG, Farrell M. Carbamazepine for cocaine dependence. Cochrane Database Syst Rev. 2009;1:CD002023.

63. Minozzi S, Amata L, Davoli M, et al. Anticonvulsants for cocaine dependence. Cochrane Database Syst Rev. 2008;2:CD006754.

64. Llopis Llacer JJ, Castillo Aquilella A. Efficacy of oxcarbazepine treatment in patients diagnosed with cocaine abuse/dependence. Adicciones. 2008;20(3):263-270. In Spanish.

65. Zullino DF, Khazaal Y, Hattenschwiler J, Borgeat F, Besson J. Anticonvulsant drugs in the treatment of substance withdrawal. Drugs Today. 2004;40(7):603-619.

66. Karila L, Reynaud M, Aubin HJ, et al. Pharmacological treatment for cocaine dependence: is there something new? Curr Pharm Des. 2011; 17(14):1359-1368.

67. Papapetropoulos S, Singer C. Improvement of cervivo-trunco-brachial segmental dystonia with topiramate. J Neurol. 2006;253(4):535-536.

68. Fahn S. Systemic therapy of dystonia. Can J Neurol Sci. 1987; 14(Suppl 3):528-532.

69. Bradbury AJ, Bentick B, Todd PJ. Dystonia associated with carbamazepine toxicity. Postgrad Med J. 1982;58(682):525-526.

70. Richter A, Löschmann PA, Löscher W. The novel antiepileptic drug, lamotrigine, exerts prodystonic effects in a mutant hamster model of generalized dystonia. Eur J Pharmacol. 1994;264(3):345-351.

71. Linazasoro Cristobal G. Efficacy and tolerance of gabapentin in dystonia and hemifacial spasm: a pilot study. Rev Neurol. 2001;33(5):408-410. In Spanish.

72. Pina MA, Modrego PJ. Dystonia induced by gabapentin. Ann Pharmacother. 2005;39(2):380-382.

73. Tekin S, Aykut-Binogöl C, Tanridağ T, Aktan S. Antiglutamatergic therapy in Alzheimer's disease - effects of lamotrigine. Short communication. J Neural Transm. 1998;105(2-3):295-303.

74. Mowla A, Pani A. Comparison of topiramate and risperidone for the treatment of behavioral disturbances of patients with Alzheimer's disease: a double-blind, randomized clinical trial. J Clin Psychopharmacol. 2010;30(1):40-43.

75. Ballard C, Corbett A, Chitramohan R, Aarsland D. Management of agitation and aggression associated with Alzheimer's disease: controversies and possible solutions. Curr Opin Psychoatry. 2009;22(6):532-540.

76. Kim Y, Wilkins KM, Tampi RR. Use of gabapentin in the treatment of behavioural and psychological symptoms in dementia: a review of the evidence. Drugs Aging. 2008;25(3):187-196.

77. Sommer OH, Aga O, Cvancarova M, Olsen IC, Selbaek G, Engedal K. Effect of oxcarbazepine in the treatment of agitation and aggression in severe dementia. Dement Geriatr Cogn Disord. 2009;27(2):155-163.

78. Spacey S, Adams P. Familial paroxysmal kinesigenic dyskinesia. In: Pagon RA, Bird TD, Dolan CR, Stephens K, editors. Gene Reviews [Internet]. [Updated March 31, 2011]. Seattle, WA: University of Washington; 1993-2005.

79. Raymond D, Ozelius L. Myoclonus-dystonia. In: Pagon RA, Bird TD, Dolan CR, Stephens K, editors. Gene Reviews [Internet]. [Updated December 19, 2005]. Seattle, WA: University of Washington; 1993-2003.

\section{Dovepress}

EMBase, Scopus and the Elsevier Bibliographic databases. The manuscript management system is completely online and includes a very quick and fair peer-review system, which is all easy to use. Visit http://www.dovepress.com/testimonials.php to read real quotes from published authors. 